\title{
Environmental offsets and production externalities under monopolistic competition
}

\author{
Masatoshi Yoshida ${ }^{1,2} \cdot$ Stephen J. Turnbull ${ }^{3}$ (D) Mitsuru Ota ${ }^{3}$
}

Accepted: 24 August 2021 / Published online: 7 January 2022

(c) The Author(s), under exclusive licence to Springer Science+Business Media, LLC, part of Springer Nature 2022

\begin{abstract}
In a monopolistically competitive model with production externalities, where individuals voluntarily provide offsets which compensate for degradation of environmental quality caused by their income earning activities, this paper examines how an increase in the population size affects the equilibrium levels of environmental quality, offsets, and net contributions. Whether labor supply is institutionally constrained or not, as the population size increases, environmental quality decreases and converges to zero. However, since offsets increase and converge to the degradation rate of environmental quality, the carbon neutrality theorem holds: net contributions are zero. These results are independent of the specification of the utility function.
\end{abstract}

Keywords Environmental offset · Carbon neutrality · Voluntary contribution · Monopolistic competition

JEL Classification D62 $\cdot \mathrm{H} 41 \cdot \mathrm{Q} 50$

\section{Introduction}

An environmental offset is a voluntary effort by an economic agent to compensate for a decrease in environmental quality due to irreversible emissions discharged by his economic activities through his own contributions to improvement in environmental quality. From a theoretical point of view, environmental offsets can be regarded as voluntary contributions to public good provision in the presence of environmental externalities. The problem of voluntary provision of offsets has

Stephen J. Turnbull

turnbull@sk.tsukuba.ac.jp

1 University of Tsukuba, Tsukuba, Japan

2 Research Center for Urban Housing Sciences, Tokyo, Japan

3 Associate Professor of Policy and Planning Sciences Faculty of Engineering, Information and Systems, University of Tsukuba, 1-1-1 Tennodai, Tsukuba, Ibaraki 305-8573, Japan 
been considered by Yoshida (1998), Shibata (1998), Ihori (1999), Vicary (2000), and Kotchen (2009). ${ }^{1}$ Shibata (1998) studied this problem in a model with production externalities on the environment. ${ }^{2}$ However, the other researchers examined the problem in partial equilibrium models or general equilibrium models of perfect competition with consumption externalities, where the polluting consumption goods are homogeneous ones supplied by dirty providers without market power.

Recently, Yoshida and Turnbull (2021) have reconsidered the problem of voluntary provision of offsets in a general equilibrium model of monopolistic competition, where environmental degradation is caused by individuals' consumption of differentiated goods produced by monopolistic firms with market power. ${ }^{3}$ They have explored how an increase in the population size affects environmental quality, offsets, and net contributions, and have shown that while the comparative static results depend on the specification of the utility function, the offsets are independent of this specification in a large economy with many individuals and "carbon neutrality" holds: net contributions are zero. Will the same results hold when environmental degradation is caused by production externalities? The purpose of this paper is to examine this problem in a monopolistically competitive model similar to the Yoshida-Turnbull model.

Shibata (1998) assumes that an income-earning activity of each individual causes environmental degradation but he can use two methods to offset the degradation. The first is to reduce his earning activity by increasing leisure which is a non-polluting activity. The second is to expend income on purchase of an environmental good and his own abatement activity. The effectiveness of these methods depends on whether labor supply is institutionally constrained or not. When labor supply is constrained, offsets via leisure and the abatement activity are not available, because pollutants have been already emitted in the environment. Thus, the only effective method is to buy the environmental good. On the other hand, when labor is not constrained, the method of purchasing the environmental good is inefficient compared to increasing leisure or the abatement activity, because the marginal cost of removing a unit of pollutant already emitted is larger than that of reducing emission of a unit of pollutant. Since the abatement activity has no positive utility, it is inferior to leisure. Therefore, the only efficient method is to adjust the scale of earning activity by leisure. Such individual reductions in productive activity to achieve social goals have come into prominence during the COVID pandemic recently as businesses, consumers, and workers have been asked to reduce activities that involve gathering in high-density space such as offices. One response to that is remote work, which managements complain makes supervision harder and leads to decreased

\footnotetext{
${ }^{1}$ For the problem of voluntary provision of public goods in the standard model without environmental externalities, see Bergstrom et al. (1986) and Andreoni (1988).

${ }^{2}$ Shibata (1998) reexamined the neutrality theorem for public goods and showed that the Nash equilibrium level of a public bad is independent not only of the wealth distribution of individuals who contribute to reduce quantity of the bad but also of their aggregate wealth.

${ }^{3}$ In monopolistically competitive models, Pecorino (2009), Mondal (2013), and Bag and Mondal (2014) considered how the aggregate provision level of public goods depends on the population size.
} 
productivity. We note that remote work has been recommended for decades as an environmentally friendly alternative to commuting as well.

We follow the Shibata (1998) model of income-earning activity and introduce imperfection competition in the consumption good industry, while the environmental good is produced under perfect competition. We conduct the analysis based on the Yoshida-Turnbull (2021) social demand and supply approach giving environmental quality as functions of the number of monopolistically competitive firms. The social demand function is derived from individuals' demand functions for environmental quality and the social supply function shows the feasible level of environmental quality. Environmental quality and the number of the firms which simultaneously satisfy the social demand and supply functions are their equilibrium levels. In order to examine the existence and uniqueness of an interior equilibrium, where offsets are positive, we specify the utility function consisting of environmental quality and differentiated goods as follows: (i) the CES utility function, which includes the Cobb-Douglas (CD) utility function, (ii) the Krugman (1980)-Pecorino (2009) (KP) utility function, and (iii) the Krugman (1981)-Mondal (2013) (KM) utility function. After demonstrating that for each utility function, there is a unique equilibrium solution such that environmental quality and the number of the firms are positive, we examine the comparative static effects of the population size on the environmental variables: environmental quality, offsets, and net contributions, and compare the results with those in the Yoshida-Turnbull model with consumption externalities.

We show that the comparative static analysis of the population size with production externalities is different from the analysis with consumption externalities. Irrespective of the level of environmental externalities, an increase in the population size decreases the social demand for environmental quality. However, the effect on the social supply depends on the type of externalities. With production externalities, when labor supply is endogenous (exogenous), since pollutants emitted are perfectly (imperfectly) cancelled by an increase in the aggregate offset, the increase in the population size does not affect (decreases) the social supply of environmental quality. Thus, environmental quality is decreasing in the population size, but offsets and net contributions are increasing in it. These results are independent of the specification of the utility function. On the other hand, with consumption externalities, the results are affected by this specification. In the KP case, since the equilibrium level of environmental quality is determined by the social demand function, it is decreasing in the population size. However, in the CES and KM cases, an increase in the population size increases the social supply of environmental quality. Thus, if the equilibrium level of environmental quality is greater (smaller) than its ambient level, then environmental quality is increasing (decreasing) in the population size.

We further explore what characteristics the environmental variables have in a large economy with many individuals. We show that with production externalities, as the population size increases, environmental quality monotonically decreases and converges to zero. However, since offsets monotonically increase and converge to the degradation rate of environmental quality, the carbon neutrality theorem holds: net contributions are zero in the large economy. On the other hand, with consumption externalities, the neutrality theorem holds, but characteristics of environmental quality and offsets are different: environmental quality depends on the specification 
of the utility function and offsets are affected by not only the degradation rate but also the marginal cost of monopolistic production and the substitution elasticity between differentiated goods.

We also analyze the comparative statics of the degradation rate of environmental quality. In the interesting case where labor supply is not constrained, since an increase in this parameter increases the price of the composite good consisting of differentiated goods, the social demand for environmental quality increases. However, since the social supply decreases with a reduction in the aggregate offset, the results depend on the specification of the utility function: (a) in the CD and KM cases, offsets are increasing in the degradation rate but environmental quality and net contributions are independent of it, (b) in the CES case, (i) if environmental quality and the composite good are gross substitutes, then all environmental variables are increasing in the degradation rate and (ii) if they are gross complements, then environmental quality and net contributions are decreasing in the degradation rate, and (c) in the KP case, the result is the same as (i) in the CES case. These comparative static results are the same as those in the Yoshida-Turnbull model.

This paper is organized as follows. Section 2 develops a model of environmental offsets with production externalities. Section 3 characterizes an equilibrium solution and specifies several utility functions. Section 4 analyzes the comparative statics of some parameters. Section 5 summarizes the comparative static results with consumption externalities and compares them with those with production externalities. Section 6 contains some concluding remarks.

\section{A model of environmental offsets with production externalities}

This section formulates a general equilibrium model with production externalities on the environment. Individuals provide labor to goods production which decreases environmental quality, but this degradation can be mitigated through voluntary provision of offsets by the individuals. This model consists of identical individuals, perfectly competitive firms, and monopolistically competitive firms. Each individual derives his utility from leisure, differentiated goods, and environmental quality. Each perfectly competitive firm supplies the environmental good and each monopolistically competitive firm supplies one variety among the differentiated goods.

\subsection{Perfectly competitive firms}

We normalize the number of identical perfectly competitive firms to unity. The representative firm produces the environmental good $Y$ by using labor $l^{Y}$ subject to the constant returns to scale technology: $Y=\alpha l^{Y}$, where $\alpha$ is the constant marginal (average) productivity of labor. Let labor be the numeraire, i.e., the wage rate is $w=1$. Then, since the market is competitive and the firm maximizes its profit, the equilibrium profit is zero. Therefore, the price of the environmental good is equal to the marginal cost of this good, i.e., $\alpha^{-1}$. 


\subsection{Identical individuals}

There are $L$ individuals and the representative individual $j$ has a utility function:

$$
u_{j}=U\left(C_{j}, G\right)+V\left(h_{j}\right)
$$

where $C_{j}$ is a composite good consisting of $N$ differentiated goods $\left(\mathbf{x}_{j}=\left\{x_{i j}\right\}_{i=1}^{N}\right), G$ is environmental quality, and $h_{j}$ is leisure. The utility function is twice differentiable and strictly quasi-concave with positive but diminishing marginal utilities $\left(U_{C}, U_{G}\right.$, $V_{h}$ ). The composite good is the CES-aggregation of $\mathbf{x}_{j}$ :

$$
C_{j}=F\left(\mathbf{x}_{j}\right)=N\left[\sum_{i=1}^{N} N^{-1} x_{i j}^{(\theta-1) / \theta}\right]^{\theta /(\theta-1)},
$$

where $\theta>1$ is the elasticity of substitution between any two goods. He chooses $\mathbf{x}_{j}$ to minimize $\mathbf{p}^{\prime} \mathbf{x}_{j}$ subject to $C_{j}=F\left(\mathbf{x}_{j}\right)$ for a given level of $C_{i}$, where $\mathbf{p}=\left\{p_{i}\right\}_{i=1}^{N}$ is the price vector of $\mathbf{x}_{j}$. The demands for $\mathbf{x}_{j}$ are

$$
x_{i j}=N^{-1}\left(P_{C} / p_{i}\right)^{\theta} C_{j} \text {, where } P_{C}=N^{-1}\left(N^{-\theta} \sum_{i=1}^{N} p_{i}^{1-\theta}\right)^{1 /(1-\theta)} .
$$

It holds that $\mathbf{p}^{\prime} \mathbf{x}_{j}=P_{C} C_{j}$.

The representative individual is endowed with one unit of labor. Following Shibata (1998), we now assume that his income earning activity causes a reduction in environmental quality by $\beta$ units. This assumption implies that pollutants are produced as a byproduct in the production process of goods. Then, it holds that $z_{j}=\beta\left(1-h_{i}\right)$, where $1-h_{j}$ is his labor income and $z_{i}$ is the quantity of pollutants emitted in the environment. It follows from $\beta>0$ and $0 \leq h_{j}<1$ that $z_{j}>0$. However, he can ameliorate this degradation of environmental quality by the following two methods. The first is to reduce his earning activity by increasing leisure which is a non-polluting activity. The second is to expend income on purchase $y_{j}$ of the environmental good and his own abatement activity $f_{j}$ for reducing emissions of pollutants. Therefore, his offsets and net contributions are given by $e_{j}=\beta h_{j}+y_{j}+f_{j}$ and $g_{j}=e_{j}-\beta$. Environmental quality is defined by

$$
G=\bar{G}+\sum_{j=1}^{L} g_{j}
$$

where $\bar{G}>0$ is the ambient level of environmental quality. Since the optimal demand for environmental quality depends on whether labor is institutionally constrained or not, we analyze exogenous and endogenous cases of labor supply separately in the utility maximization problem.

\subsubsection{Exogenous labor supply}

In this case, each individual's labor supply is constrained by institutional arrangements or otherwise. Since the quantity of pollutants emitted is given by $\bar{z}=\beta(1-\bar{h})$, he cannot reduce $\bar{z}$ by an adjustment of leisure. He also cannot reduce it by his own 
abatement activity, because the pollutants have been already emitted in the environment. The only way to offset a decrease in environmental quality is to purchase the environmental good from the market. Hence, since it follows from $f_{j}=0$ that $e_{j}=\beta \bar{h}+y_{j}$ and $g_{j}=y_{j}-\beta(1-\bar{h})$, the level of environmental quality is

$$
G=\bar{G}+\sum_{j=1}^{L}\left[y_{j}-\beta(1-\bar{h})\right] .
$$

Since the wage rate and the price of the environmental goods are equal to 1 and $\alpha^{-1}$, respectively, the budget constraint is written as

$$
P_{C} C_{j}+\alpha^{-1} y_{j}=1-\bar{h} .
$$

It follows from (2) that $g_{j}=(\alpha-\beta)(1-\bar{h})-\alpha P_{C} C_{j}$. It should be now noted that $\alpha^{-1}$ is the marginal cost of removing a unit of pollutant already emitted, but $\beta^{-1}$ is the marginal cost of reducing emission of a unit of pollutant. Since $\alpha^{-1}$ is most likely larger than $\beta^{-1}$, we assume that $\alpha^{-1}>\beta^{-1}$, or equivalently $\beta>\alpha$. It follows from this assumption that $g_{j}<0$, so that $e_{j}<\beta$. Thus, net contributions are negative and offsets are smaller than the degradation rate of environmental quality.

The individual maximizes his utility function with respect to $C_{j}$ and $y_{j}$ subject to (1) and (2), treating the differentiated goods and offset purchases of other individuals $\left(\mathbf{x}_{k}\right.$ and $y_{k}$, where $k \neq j$ ) as fixed. Eliminating $y_{j}$ from the constraints, we can represent his utility maximization problem as ${ }^{4}$

$$
\max U\left(C_{j}, G\right)+V(\bar{h}) \text { subject to } \alpha P_{C} C_{j}+G=m_{j},
$$

where $m_{j}=\bar{G}+G_{-j}+(\alpha-\beta)(1-\bar{h})$ and $G_{-j}=\sum_{k \neq j} g_{k}$. The first-order conditions for the problem (3) with respect to $C_{j}$ and $G$ are $U_{C}=\lambda_{j} \alpha P_{C}$ and $U_{G}=\lambda_{j}$, respectively, where $\lambda_{j}>0$ is the Lagrange multiplier with respect to the constraint. Thus, the optimal demand $G_{j}^{d}$ of environmental quality is represented as $G_{j}^{d}=d\left(\alpha P_{C}, m_{j}\right)$.

\subsubsection{Endogenous labor supply}

In this case, each individual determines the scale of his earning activity by choosing a level of labor supply. The quantity of pollutants emitted is $z_{j}=\beta\left(1-h_{j}\right)$. He can decrease this by not only an increase in leisure but also the following two methods. The one is his purchase of the environmental good and the other is his own abatement activity. The market price of $y_{j}$ is $\alpha^{-1}$, and the opportunity cost of $f_{j}$ is the marginal income $\beta^{-1}$ of a unit of pollutant emitted in the earning activity. He minimizes $\alpha^{-1} y_{j}+\beta^{-1} f_{j}$ subject to $y_{j}+f_{j}=\bar{e}_{j}-\bar{h}$, where $\bar{e}_{j}$ is constant. At the unique solution for this problem, it follows from $\alpha^{-1}>\beta^{-1}$ that $y_{j}=0 .^{5}$

\footnotetext{
${ }^{4}$ Although it follows from $y_{j} \geq 0$ that $G \geq \bar{G}+G_{-j}-\beta(1-\bar{h})$, we do not consider this inequality constraint in the problem (3), since we are concerned with an interior solution, where $y_{j}>0$.

${ }^{5}$ Since each individual does not purchase the environmental good in the endogenous case of labor supply, the environmental good is not produced, i.e., $Y=0$ and $l^{Y}=0$.
} 
Thus, we can represent the budget constraint and the level of environmental quality as

$$
\beta P_{C} C_{j}+f_{j}+\beta h_{j}=\beta \text { and } G=\bar{G}+\sum_{j-1}^{L}\left(f_{j}+\beta h_{j}-\beta\right)
$$

Let us now consider the following maximization problem with respect to $f_{j}$ :

$$
\max U\left(C_{j}, G\right)+V\left[\beta^{-1}\left(\bar{e}_{j}-f_{j}\right)\right] \text { subject to } f_{j} \geq 0,
$$

where $C_{j}=\left(1-\beta^{-1} \bar{e}_{j}\right) / P_{C}$ and $G=\bar{G}+G_{-j}+\bar{e}_{j}-\beta$. It follows from $V_{h}>0$ that the optimal solution for this problem is $f_{j}=0$. Thus, the abatement activity is an inferior method as compared with an adjustment of the scale of earning activity. The only efficient way to offset a decrease in environmental quality is to reduce labor supply by increasing leisure. It follows from $y_{j}=0$ and $f_{j}=0$ that $g_{j}=-\beta\left(1-h_{j}\right)<0$ and $e_{j}=\beta h_{j}<\beta$. Eliminating $h_{j}$ from (4), then we can represent the utility maximization problem as

$$
\max U\left(C_{j}, G\right)+V\left(h_{j}\right) \text { subject to } \beta P_{C} C_{j}+G=m_{j},
$$

where $m_{j}=\bar{G}+G_{-j}$. Since the budget constraint in (5) does not involve leisure $h_{j}$, the optimal demand $G_{j}^{d}$ of environmental quality is represented as $G_{j}^{d}=d\left(\beta P_{C}, m_{j}\right)$. It should be now noted that the optimal level of leisure is not derived from the utility maximization problem (5). Its level is determined by the equilibrium level of environmental quality in this model (see Section 3).

\subsection{Monopolistically competitive firms}

Technology in the production sector of the differentiated goods is subject to increasing returns to scale. Each good is produced by a single firm and there are $N$ monopolistic firms. The firms have the common cost function: $l_{i}^{X}=a+b X_{i}$ for all $i$, where $l_{i}^{X}$ is labor demand by the $i$ th firm producing output $X_{i}$, the parameter $a$ is the fixed cost, and the parameter $b$ is the marginal cost. Under the assumption that other firms do not change their behaviors, each firm sets the price $p_{i}$ to maximize its profit $\pi_{i}=p_{i} X_{i}-l_{i}^{X}$ subject to the demand function of each individual for this good and the market equilibrium condition: $X_{i}=\sum_{j=1}^{L} x_{i j}$. Assume that there is a large number of the firms, so that each firm treats the aggregate variables such as $P_{C}$ and $C_{i}$ as fixed. Then, it follows from the first-order condition for the profit maximization that $p_{i}=\bar{p}=b /\left(1-\theta^{-1}\right)$. As firms' profits are zero by free entry, it follows from $\pi_{i}=0$ that $X_{i}=\bar{X}=a b^{-1}(\theta-1)$. It should be now noted that (i) $\bar{p} \bar{X}=a \theta$ and (ii) $\bar{p}$ and $\bar{X}$ are independent of $\alpha$ and $\beta$.

\section{General equilibrium}

Following Yoshida and Turnbull (2021), this section characterizes a general equilibrium by using the social demand and supply functions of environmental quality. The social demand function is derived from the aggregation of individuals' demands for 
environmental quality. On the other hand, the social supply function shows the feasible level of environmental quality. Environmental quality and the number of monopolistically competitive firms satisfy these functions at their equilibrium levels, which in turn determine the levels of the remaining endogenous variables.

\subsection{The social demand function}

Since all individuals and all monopolistic firms have been assumed to be identical in this model, it holds that $G_{j}^{d}=G^{*}, m_{j}=m^{*}, p_{i}=p^{*}=\bar{p}, X_{i}=X^{*}=\bar{X}$, and so on. ${ }^{6}$ We represent the individual demand function of environmental quality in the equilibrium as $G^{*}=d\left(P^{*}, m^{*}\right)$, where $P^{*}=\gamma \bar{p}$ is the effective price of the composite good. It should be now noted that (i) $\gamma=\alpha$ and $m^{*}=\bar{G}+G_{-j}^{*}+(\alpha-\beta)(1-\bar{h})$ in the case of exogenous labor supply and (ii) $\gamma=\beta$ and $m^{*}=\bar{G}+G_{-j}^{*}$ in the endogenous case. Solving this demand function with respect to $m^{*}$, we obtain $m^{*}=M\left(G^{*}, P^{*}\right)$. It follows from $m^{*}-G^{*}=P^{*} C^{*}$ and $x^{*}=C^{*} / N^{*}$ that $m^{*}-G^{*}=P^{*} N^{*} x^{*}$, where $x^{*}=\bar{X} / L$ (i.e., the equilibrium condition of a differentiated good). Since this shows the relation between the aggregate demand of environmental quality and the number of monopolistic firms, we write it as $G^{*}=D\left(N^{*}\right)$ and call this the social demand function for environmental quality.

\subsection{The social supply function}

In the case of exogenous labor supply, it follows from $\alpha \bar{p} N^{*} x^{*}+y^{*}=\alpha(1-\bar{h})$ and $G^{*}=\bar{G}+L\left[y^{*}-\beta(1-\bar{h})\right]$ that $G^{*}=A-\alpha \bar{p} L x^{*} N^{*}$, where $A$ is the maximal attainable level of environmental quality, i.e., $A=\bar{G}+(\alpha-\beta) L(1-\bar{h})$. Since this shows the relation between the aggregate supply of environmental quality and the number of monopolistic firms, we write it as $G^{*}=S\left(N^{*}\right)$ and call this the social supply function. Similarly, in the endogenous case, it follows from $\bar{p} N^{*} x^{*}=1-h^{*}$ and $G^{*}=\bar{G}-L \beta\left(1-h^{*}\right)$ that $G^{*}=A-\beta \bar{p} L x^{*} N^{*}$, where $A=\bar{G}$. In both cases, an increase in the aggregate expenditure on differentiated goods $\left(P L x^{*} N^{*}\right)$ reduces the aggregate offset, so that the feasible level of environmental quality decreases.

\subsection{Characterization of the equilibrium solution}

The equilibrium levels of environmental quality and the number of monopolistic firms must satisfy the following simultaneous equations:

$$
\begin{gathered}
L\left[M\left(G^{*}, \gamma \bar{p}\right)-G^{*}\right]=\gamma \alpha \theta N^{*}, \\
G^{*}=A-\gamma a \theta \bar{X} N^{*},
\end{gathered}
$$

\footnotetext{
${ }^{6}$ We mark the equilibrium levels of endogenous variables in the model with an asterisk (*).
} 
where (i) $\gamma=\alpha$ and $A=\bar{G}+(\alpha-\beta) L(1-\bar{h})<\bar{G}$ in the case of exogenous labor supply and (ii) $\gamma=\beta$ and $A=\bar{G}$ in the endogenous case. Since the number of monopolistic firms must be positive in the equilibrium, we derive $G^{*}<A$ from (7). It follows from this inequality and $A \leq \bar{G}$ that

$$
G^{*}<A \leq \bar{G} .
$$

Therefore, the equilibrium level of environmental quality is smaller than its ambient level. If $\bar{G}=0$, then it follows (8) that $G^{*}<0$, so that a general equilibrium such that $N^{*}>0$ and $G^{*} \geq 0$ does not exist in this model. For the existence of such an equilibrium, we need the condition that $A>0$. Since we have assumed that $\bar{G}>0$, this condition is satisfied in the case of endogenous labor supply, but we must set the stronger assumption: $\bar{G}>(\beta-\alpha) L(1-\bar{h})>0$ in the exogenous case.

Given the equilibrium level of environmental quality, the equilibrium levels of offsets and net contributions in the exogenous and endogenous cases of labor supply are

$$
\begin{gathered}
e^{*}=y^{*}+\beta \bar{h}>0, g^{*}=y^{*}-\beta(1-\bar{h})<0, \text { and } y^{*}=\alpha(1-\bar{h})-\left(m^{*}-G^{*}\right), \\
e^{*}=\beta h^{*}>0, g^{*}=-\beta\left(1-h^{*}\right)<0, \text { and } h^{*}=1-\beta^{-1}\left(m^{*}-G^{*}\right),
\end{gathered}
$$

where $m^{*}-G^{*}=\left(A-G^{*}\right) / L$. Note that (i) offsets are positive but net contributions are negative and (ii) since $m^{*}-G^{*}$ is equal to $P^{*} C^{*}$, a decrease in $m^{*}-G^{*}$ increases $y^{*}$ and $h^{*}$ through the budget constraint, so that $e^{*}$ and $g^{*}$ are decreasing in $m^{*}-G^{*}$.

\subsection{Specification of the utility function}

In this subsection, we assume the following functional forms to study the existence and uniqueness of the interior equilibrium: the CES utility function, the Krugman (1980)-Pecorino (2009) utility function, and the Krugman (1981)-Mondal (2013) utility function:

$$
\begin{gathered}
U\left(C_{j}, G\right)=\left[\epsilon C_{j}^{(\sigma-1) / \sigma}+(1-\epsilon) G^{(\sigma-1) / \sigma}\right]^{\sigma /(\sigma-1)}, \\
U\left(\mathbf{x}_{j}, G\right)=\sum_{i=1}^{N} x_{i j}^{(\theta-1) / \theta}+H(G), \\
U\left(\mathbf{x}_{j}, G\right)=\ln \left[\sum_{i=1}^{N} x_{i j}^{(\theta-1) / \theta}\right]^{\theta /(\theta-1)}+H(G),
\end{gathered}
$$

where $\sigma>0,0<\epsilon<1, H^{\prime}>0, H^{\prime \prime}<0, H^{\prime}(\infty)=0$, and $H^{\prime}(0)=\infty$.

\subsubsection{The CES utility function}

It follows from (11) that the optimal demand function of environmental quality is $G_{j}^{d}=(1-c) m_{j}$, where $c$ is the marginal propensity to consume out of full income. 
Fig. 1 The equilibrium in the case of the CES utility function

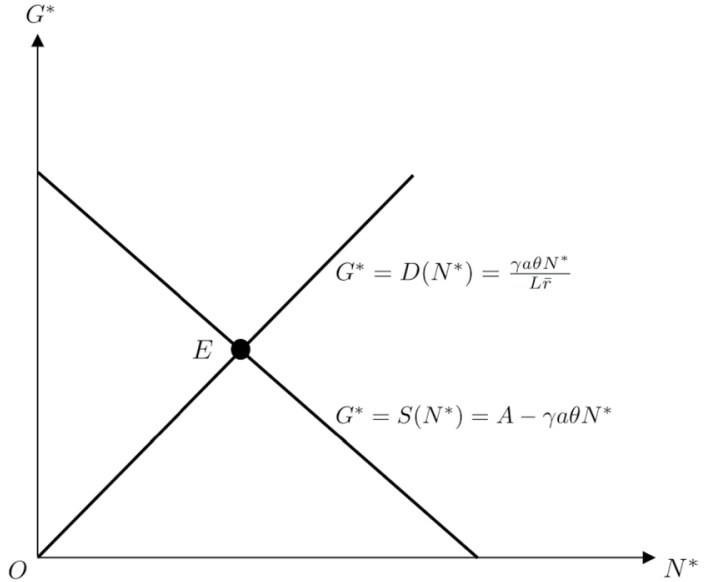

Define the expenditure ratio of the composite good to environmental quality by $r \equiv P C / G=c /(1-c)$. Then, it holds that

$$
m^{*}-G^{*}=\bar{r} G^{*}, \text { where } \bar{r}=\left[\epsilon^{-1}(1-\epsilon)\right]^{\sigma}(\gamma \bar{p})^{1-\sigma} .
$$

It follows from (6) and (14) that the social demand function is

$$
G^{*}=D\left(N^{*}\right)=\frac{\gamma a \theta}{L \bar{r}} N^{*} .
$$

As is illustrated in Fig.1, the social supply function (7) is shown by the downward sloping line, but the social demand function (15) is shown by the upward sloping line through the origin. Solving them with respect to $G^{*}$ and $N^{*}$, we obtain their equilibrium levels:

$$
G^{*}=\frac{A}{1+\bar{r} L} \text { and } N^{*}=\frac{A \bar{r} L}{\gamma a \theta(1+\bar{r} L)}
$$

The condition $A>0$ assures that $G^{*}>0$ and $N^{*}>0$.

\subsubsection{The Krugman-Pecorino utility function}

Using the aggregation $C_{j}=F\left(\mathbf{x}_{j}\right)$ of $\mathbf{x}_{j}$ into $C_{j}$, we can transform the KP utility function (12) to

$$
U\left(C_{j}, G\right)=N^{1+\theta^{-1}} C_{j}^{1-\theta^{-1}}+H(G) .
$$

The first-order conditions for the utility maximization problem are summarized as

$$
\left(1-\theta^{-1}\right)\left(\frac{\gamma \bar{p} N^{*}}{m^{*}-G^{*}}\right)^{\theta^{-1}}=\gamma \bar{p} H^{\prime}\left(G^{*}\right) .
$$

It follows from (6) and (17) that 
Fig. 2 The equilibrium in the case of the Krugman-Pecorino utility function

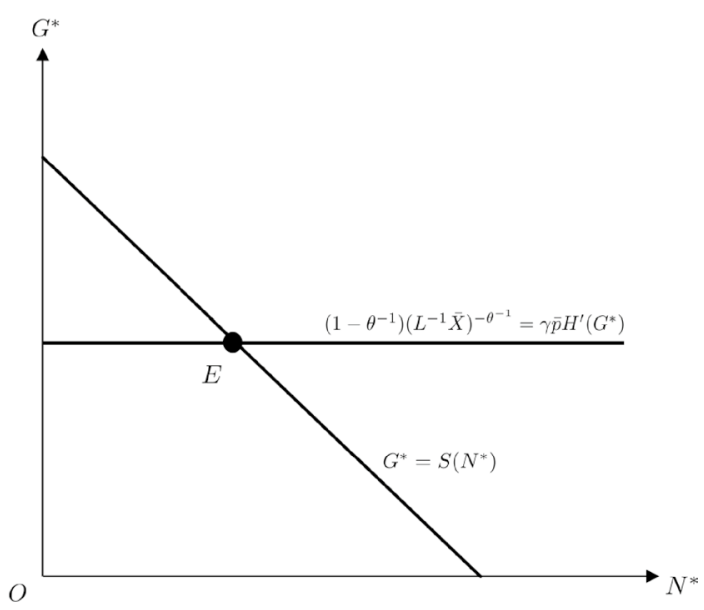

$$
\left(1-\theta^{-1}\right)\left(\frac{L}{\bar{X}}\right)^{\theta^{-1}}=\gamma \bar{p} H^{\prime}\left(G^{*}\right) .
$$

The positive level of $G^{*}$ is uniquely determined by (18). In Fig. 2, the social demand function is shown by the horizontal line. The number of the firms is derived from the social supply function (7).

\subsubsection{The Krugman-Mondal utility function}

We can represent the KM utility function (13) as

$$
U\left(C_{j}, G\right)=\ln C_{j}+\ln N^{\theta /(\theta-1)-1}+H(G) .
$$

The first-order conditions are summarized as

$$
m^{*}-G^{*}=\frac{1}{H^{\prime}\left(G^{*}\right)} .
$$

Therefore, the social demand function is given by

$$
G^{*}=D\left(N^{*}\right)=H^{\prime-1}\left(\frac{1}{\gamma \bar{p} N^{*} x^{*}}\right) .
$$

The demand function (20) is shown by the upward sloping curve in the $\left(N^{*}, G^{*}\right)$ space. The unique equilibrium level of environmental quality is determined by

$$
\frac{L}{A-G^{*}}=H^{\prime}\left(G^{*}\right)
$$

It follows from (21) and $A>G^{*}$ that $G^{*}>0$. 


\section{Comparative statics}

This section studies how the population size affects the equilibrium levels of the environmental variables: environmental quality, offsets, and net contributions, and explores what characteristics they have when the population size increases without bound. The comparative statics of the degradation rate of environmental quality are also analyzed.

\subsection{The population size}

For a given number of monopolistic firms, since the supply level of a particular differentiated good is constant in the equilibrium, an increase in the population size decreases the demand level of this good by each individual. Therefore, since his demand for environmental quality increases, the social demand function shifts downward. The response of the supply function to a change in the population varies depending on whether labor supply is exogenous or endogenous. The social supply function does not shift when labor supply is endogenous, but it shifts downward when it is exogenous. Thus, the increase in the population size decreases the equilibrium level of environmental quality in all cases. We can mathematically confirm this result. It follows from (15) in the CES case, (17) in the KP case, and (20) in the KM case that

$$
G_{L}^{*}=\frac{A_{L}(1+\bar{r} L)-A \bar{r}}{(1+\bar{r} L)^{2}}, G_{L}^{*}=\frac{K \theta^{-1} L^{(1-\theta) / \theta}}{H^{\prime \prime}}, \text { and } G_{L}^{*}=\frac{L A_{L}-\left(A-G^{*}\right)}{L-H^{\prime \prime}\left(A-G^{*}\right)},
$$

respectively, where $G_{L}^{*} \equiv \partial G^{*} / \partial L$. It follows from $A>0, A_{L} \leq 0, A>G^{*}, H^{\prime \prime}<0$, and $K>0$ that $G_{L}^{*}>0$ in all cases. From (8) and (9), the effects of the population size on offsets and net contributions are

(i) $e_{L}^{*}=g_{L}^{*}=y_{L}^{*}$ and $y_{L}^{*}=-\partial\left(m^{*}-G^{*}\right) / \partial L$ in the case of exogenous labor supply,

(ii) $e_{L}^{*}=g_{L}^{*}=\beta h_{L}^{*}$ and $h_{L}^{*}=-\beta^{-1} \partial\left(m^{*}-G^{*}\right) / \partial L$ in the endogenous case.

In the CES case, it follows from (13) that $y_{L}^{*}=-\bar{r} G_{L}^{*}>0$ and $h_{L}^{*}=-\beta^{-1} \bar{r} G_{L}^{*}>0$. Thus, whether labor supply is exogenous or not, it holds that $e_{L}^{*}=g_{L}^{*}>0$. We can derive the same results from (13) and $N_{L}^{*}<0$ in the KP case and from (18) in the $\mathrm{KM}$ case. These results are summarized in the following proposition and are illustrated in Fig.3.

Proposition 1 In the general equilibrium model with production externalities on the environment due to individuals' income-earning activities, whether labor supply is exogenous or not, the following comparative static results of the population size hold:

(a) Environmental quality is decreasing in the population size. 
Fig. 3 The comparative statics of the population size: Production externalities

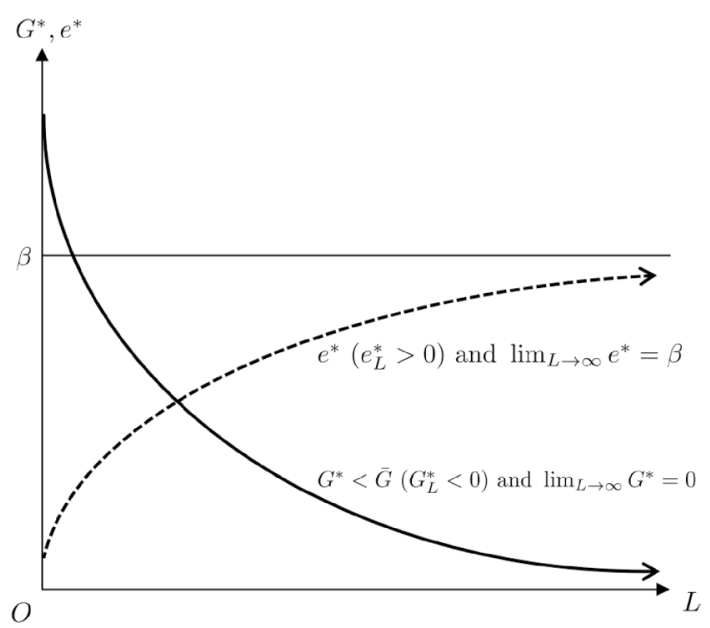

(b) Offsets and net contributions are increasing in the population size.

These results are independent of the specification of the utility function.

In spite of the positive effect of the population size on net contributions, an increase in the population size degrades the environment. Although this result seems to be paradoxical, we can explain it as follows. It follows from $G^{*}=\bar{G}+L g^{*}$ that $G_{L}^{*}=g^{*}+L g_{L}^{*}$. The first and second terms in the RHS of this equation are the direct and indirect effects of the population size on environmental quality, respectively. It follows from $g^{*}<0$ in this model that the direct effect decreases environmental quality. If $g_{L}^{*}>0$, then the indirect effect increases environmental quality. However, the direct effect dominates the indirect effect, so that the level of environmental quality decreases.

\subsection{The limit properties of the environmental variables}

This subsection characterizes the equilibrium levels of the environmental variables when the population size increases without bound. When labor is endogenously supplied, it follows from (15) and (20) that $\lim _{L \rightarrow \infty} G^{*}=0$ in the CES and $\mathrm{KM}$ cases. However, when it is exogenously supplied, it follows from $\beta>\alpha$ that $\lim _{L \rightarrow \infty} G^{*}<0$, so that the equilibrium level of environmental quality converges to zero at a finite population size. On the other hand, in the KP case, whether labor supply is exogenous or not, it follows from (17) and $H^{\prime}(0)=\infty$ that $\lim _{L \rightarrow \infty} G^{*}=0$. Contributions also converge. It follows from (9) and (10) that $\lim _{L \rightarrow \infty} y^{*}=\beta(1-\bar{h})$ and $\lim _{L \rightarrow \infty} h^{*}=1$, so that $\lim _{L \rightarrow \infty} e^{*}=\beta$ and $\lim _{L \rightarrow \infty} g^{*}=0$. These results are summarized in the following proposition and are illustrated in Fig.3.

Proposition 2 When the population size increases without bound, the following limit properties of the environmental variables hold: 
(a) If labor supply is endogenous, then $\lim _{L \rightarrow \infty} G^{*}=0$ in the CES and KM cases, but if it is exogenous, then $G^{*}$ converges to zero at a finite population size. On the other hand, whether labor supply is exogenous or not, $\lim _{L \rightarrow \infty} G^{*}=0$ in the KP case.

(b) Whether labor supply is exogenous or not, $\lim _{L \rightarrow \infty} e^{*}=\beta$ and $\lim _{L \rightarrow \infty} g^{*}=0$ in all cases, so that offsets are positive and carbon neutrality holds: net contributions are zero.

\subsection{The degradation rate of environmental quality}

When labor is endogenously supplied, since an increase in the degradation rate $\beta$ increases the price of the composite good, the social demand function of environmental quality shifts upward. However, the social supply function shifts downward by a decrease in the aggregate offset. Thus, the increase in $\beta$ has opposite effects on these functions. In the CES case, it follows from (22) and $A_{\beta}=0$ that the sign of $G_{\beta}^{*}$ depends on that of $\bar{r}_{\beta}$. If $\rho>(<) 1$, where $\rho$ is the elasticity of substitution between environmental quality and the composite good, then $G_{\beta}^{*}>(<) 0$ and $g_{\beta}^{*}>(<) 0$. It follows from $e_{\beta}^{*}=g_{\beta}^{*}+1$ that if $\rho>1$, then $e_{\beta}^{*}>0$, but if $\rho<1$, then the sign of $e_{\beta}^{*}$ is indeterminate. If $\rho=1$ (i.e., the CD case), then it follows from $\bar{r}_{\beta}=0$ that $G_{\beta}^{*}=0$, $g_{\beta}^{*}=0$, and $e_{\beta}^{*}>0$. These results also hold in the KM case. However, in the KP case, it follows from (17) that $G_{\beta}^{*}>0$, so that $g_{\beta}^{*}>0$ and $e_{\beta}^{*}>0$.

On the other hand, when labor is exogenously supplied, since an increase in $\beta$ does not affect the effective price of the composite good, the social demand function is unchanged in each case. However, since the social supply function shifts downward by $A_{\beta}<0$, it holds that $G_{\beta}^{*}<0$ and $g_{\beta}^{*}=L^{-1} G_{\beta}^{*}<0$ in the CES and KM cases. In the CES case, it follows from $y_{B}^{*}=-\bar{\gamma} G_{B}^{*}>0$ that $e_{B}^{*}=y_{B}^{*}+\bar{h}>0$. The same results hold in the KM case. However, in the KP case, it holds that $G_{\beta}^{*}=0, g_{\beta}^{*}=0$, $e_{\beta}^{*}=1>0$, and $y_{\beta}^{*}=1-\bar{h}>0$.

These results are summarized in the following proposition.

Proposition 3 The comparative static results of the degradation rate are:

(a) In the CD and KM cases, (i) when labor supply is endogenous, environmental quality and net contributions are independent of the degradation rate but offsets are increasing in this rate and (ii) when it is exogenous, environmental quality and net contributions are decreasing but offsets are increasing.

(b) In the CES case, when labor supply is endogenous, (i) if environmental quality and the composite good are substitutes, then all environmental variables are increasing in the degradation rate and (ii) if they are complements, then environmental quality and net contributions are decreasing but the effect on offsets is ambiguous. When labor supply is exogenous, the results are the same as (ii) in the CES case. 
(c) In the KP case, (i) when labor supply is endogenous, the result is the same as ( $i)$ in the CES and (ii) when it is exogenous, net contributions are increasing in the degradation rate but environmental quality and offsets are independent of this rate.

\section{Consumption externalities}

This section summarizes a similar general equilibrium model developed by Yoshida and Turnbull (2021) with environmental externalities due to consumption of differentiated goods and compares the comparative static results of the population size and the degradation rate with Propositions 1-3 in Section 4.

\subsection{The Yoshida-Turnbull model}

This model is briefly described as follows. The utility function and the budget constraint of the representative individual $j$ are given by

$$
u_{j}=U\left(C_{j}, G\right) \text { and } \mathbf{q}^{\prime} \mathbf{x}_{j}+y_{j}=1,
$$

where $C_{j}=F\left(\mathbf{x}_{j}\right), \mathbf{q}$ is the price vector of differentiated goods $\mathbf{x}_{j}$, and $y_{j}$ is consumption of the environmental good. Consumption of $\mathbf{x}_{j}$ causes a reduction in environmental quality by $\beta$ units. Offsets and net contributions are $e_{j}=y_{j}$ and $g_{j}=e_{j}-\beta \sum_{i=1}^{N} x_{i j}$. Environmental quality is defined by

$$
G=\bar{G}+\sum_{i=1}^{L} y_{j}-\beta \sum_{j=1}^{L} \sum_{i=1}^{N} x_{i j}
$$

The utility maximization problem is represented as

$$
\max U\left(C_{j}, G\right) \text { subject to } P_{C} C_{j}+G=m_{j},
$$

where $m_{j}=1+\bar{G}+G_{-j}, P_{C} C_{j}=\mathbf{p}^{\prime} \mathbf{x}_{j}$, and $\mathbf{p}=\left\{q_{i}+\beta\right\}_{i=1}^{N}$ is the effective price vector of $\mathbf{x}_{j}$. The optimal demand for environmental quality is represented as $G_{j}^{d}=d\left(P_{C}, m_{j}\right)$. The production function of each monopolistic firm is $l_{i}^{X}=a+b X_{i}$. Thus, it follows from the profit maximization and the zero profit condition that $p_{i}=\bar{p}=(b+\beta) /\left(1-\theta^{-1}\right)$ and $X_{i}=\bar{X}=a(\theta-1) /(b+\beta)$.

Instead of (6) and (7), the equilibrium levels of environmental quality and the number of monopolistic firms must satisfy the following simultaneous equations:

$$
\begin{gathered}
L\left[M\left(G^{*}, \bar{p}\right)-G^{*}\right]=a \theta N^{*}, \\
G^{*}=A-a \theta N^{*},
\end{gathered}
$$

where $A=\bar{G}+L$. It should be now noted that (i) the social supply function (23) is independent of the degradation rate, (ii) the social demand function (22) is affected 
Fig. 4 The comparative statics of the population size in the CES case: Consumption externalities

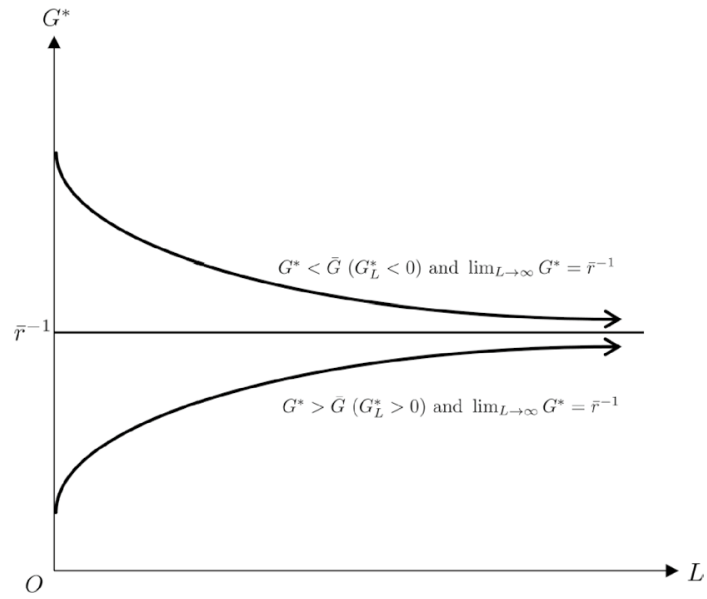

by the degradation rate, (iii) the maximal attainable level of environmental quality is $\bar{G}+L$, and (iv) it follows from (8) that $G^{*}$ can be greater than or less than $\bar{G}$.

Instead of (9) and (10), it follows from (23), $e^{*}=y^{*}=1-\bar{q} N^{*} L^{-1} \bar{X}, \bar{q}=\bar{p}-\beta$, and $g^{*}=y^{*}-\beta N^{*} L^{-1} \bar{X}$ that the equilibrium levels of offsets and net contributions are

$$
\begin{gathered}
e^{*}=1-\bar{q} \bar{p}^{-1}\left(1-g^{*}\right), \\
g^{*}=1-\left(m^{*}-G^{*}\right),
\end{gathered}
$$

where $m^{*}-G^{*}=1+L^{-1}\left(\bar{G}-G^{*}\right)$. It should be now noted that (i) $e^{*}$ and $g^{*}$ are decreasing in $m^{*}-G^{*}$ and (ii) it follows from $G^{*}=\bar{G}+L g^{*}$ that if $G^{*}-\bar{G}>(<) 0$, then $g^{*}>(<) 0$.

The specific utility functions are the same as (11)-(13). In the CES case, the social demand function and the equilibrium level of environmental quality are the same as (15) and (16), where $\gamma=1$ and $A=\bar{G}+L$. In the KM case, they are the same as (20) and (21). In the KP case, the same equation as (18) determines environmental quality.

The following comparative static results of the population size and the degradation rate are obtained by Yoshida and Turnbull (2021). Results 1-2 are illustrated in Fig.4 for the CES case.

\section{Result 1}

(a) In the CES and KM cases, if $G^{*}>(<) \bar{G}$, then environmental quality is increasing (decreasing) in the population size. It is decreasing in the KP case.

(b) In the CES and KM cases, if $G^{*}>(<) \bar{G}$, then offsets and net contributions are decreasing (increasing). In the KP case, if $G^{*}>\bar{G}$, then they are decreasing, while otherwise, the same result does not always hold. 


\section{Result 2}

(a) In the CES, KP, and KM cases, $\lim _{L \rightarrow \infty} G^{*}=\bar{r}^{-1}, \lim _{L \rightarrow \infty} G^{*}=0$, and $\lim _{L \rightarrow \infty} G^{*}=\hat{G}$, where $H^{\prime}(\hat{G})=1$, respectively.

(b) In all cases, $\lim _{L \rightarrow \infty} e^{*}=\beta \bar{p}^{-1}$ and $\lim _{L \rightarrow \infty} g^{*}=0$, so that offsets are positive and carbon neutrality holds: net contributions are zero.

\section{Result 3}

(a) In the $\mathrm{CD}$ and $\mathrm{KM}$ cases, environmental quality and net contributions are independent of the degradation rate, but offsets are increasing.

(b) In the CES case, (i) if environmental quality and the composite good are substitutes, then all environmental variables are increasing in the degradation rate and (ii) if they are complements, then environmental quality and net contributions are decreasing in it, but the effect on offsets is ambiguous.

(c) The result in the KP case is the same as (i) in the CES.

\subsection{Comparison of production externalities with consumption externalities}

This subsection compares Propositions 1-3 with Results 1-3 to investigate how production and consumption externalities affect the comparative static results of the population size and the degradation rate of environmental quality.

\subsubsection{The population size}

First, compare the effects on environmental quality. Although an increase in the population size decreases the social demand of environmental quality, the effect on the social supply depends on the type of externality. With production externalities, when labor supply is endogenous (exogenous), since the pollutants emitted are perfectly (imperfectly) cancelled by a rise in the aggregate offset, the increase in the population size does not affect (decreases) the feasible level of environmental quality. Thus, the equilibrium level of environmental quality is decreasing in the population size in all cases (Proposition 1-(a)). With consumption externalities, the same result holds in the KP case. However, in the CES and KM cases, since the increase in the population size increases the feasible level of environmental quality, the equilibrium level of environmental quality is affected by the social demand and supply functions. The results depend on whether the equilibrium level of environmental quality is greater than its ambient level: if $G^{*}>(<) \bar{G}$, then $G_{L}^{*}>(<) 0$ (Result 1-(a)).

Next, compare the effects on offsets and net contributions. With production externalities, an increase in the population size increases these offsets by a decrease in the composite good's demand by each individual (Proposition 1-(b)). With consumption externalities, since it follows from (24) and (25) that $e_{L}^{*}=\bar{q} \bar{p}^{-1} g_{L}^{*}, e_{L}^{*}$ and $g_{L}^{*}$ have the same signs. In the CES case, since it follows from (14) that $g_{L}^{*}=-\bar{r} G_{L}^{*}$, the sign of $g_{L}^{*}$ is opposite to that of $G_{L}^{*}$ (Result 1-(b)). The same result holds in the KM case, but in the KP case, if $G^{*}>\bar{G}$, then $g_{L}^{*}<0$. 


\subsubsection{The limit properties}

The limit properties of environmental quality depend on the type of environmental externalities. With production externalities, the equilibrium level of environmental quality monotonically decreases and converges to zero in all cases (Proposition 2-(a)). On the other hand, with consumption externalities, if $G^{*}>(<) \bar{G}$ in the $\mathrm{CES}$ and KM cases, then it monotonically increases (decreases) and converges to a positive level, but in the KP case, it monotonically decreases and converges to zero (Result 2-(a)). Irrespective of the source of environmental externalities, the carbon neutrality theorem holds, but offsets in the large economy depend on whether the source of the externalies is consumption or production. With production externalities, whether labor supply is constrained or not, offsets depend on only the degradation rate (Proposition 2-(b)). Therefore, technological progress in the environmental sector decreases offsets, but they are independent of technological progress in the production sector of differentiated and environmental goods. On the other hand, with consumption externalities, offsets are affected by not only the degradation rate but also the marginal cost of monopolistic production and the substitution elasticity between two differentiated goods (Result 2-(b)).

\subsubsection{The degradation rate}

With consumption externalities, since the social demand and supply functions are independent of the degradation rate $\beta$ in the $\mathrm{CD}$ and KM cases, the equilibrium levels of environmental quality and net contributions do not depend on $\beta: G_{\beta}^{*}=0$ and $g_{\beta}^{*}=0$. However, offsets are affected by $\beta$. It follows from (24) and (25) that $e_{\beta}^{*}=\phi\left(1-g^{*}\right)+\psi G_{\beta}^{*}$, where $\phi=b /\left(1-\theta^{-1}\right) \bar{p}^{2}>0, \psi=L^{-1}\left(1-\beta \bar{p}^{-1}\right)>0$, and $1-g^{*}>0$. Thus, it follows that $G_{\beta}^{*}=0, g_{\beta}^{*}=0$, and $e_{\beta}^{*}>0$ (Result 3-(a)). On the other hand, in the CES and KP cases, the social demand function is affected by $\beta$. In the CES case, if environmental quality and the composite good are substitutes, then a reduction in $\beta$ shifts the social demand function downward. Thus, it holds that $G_{\beta}^{*}>0, g_{\beta}^{*}>0$, and $e_{\beta}^{*}>0$ (Result 3-(b)-(i)). When complements, a reduction in $\beta$ shifts the social demand function upward, and it holds that $G_{\beta}^{*}<0$ and $g_{\beta}^{*}<0$, while the sign of $e_{\beta}^{*}$ is ambiguous (Result 3-(b)-(ii)). In the KP case, since the social demand function always shifts downward, it holds that $G_{\beta}^{*}>0, g_{\beta}^{*}>0$, and $e_{\beta}^{*}>0$ (Result 3-(c)). These results are the same as those with production externalities when labor supply is endogenous (Proposition 3).

\section{Concluding remarks}

In a monopolistically competitive model with production externalities on the environment, where voluntary provision of offsets by individuals compensates for environmental degradation caused by their income earning activities, we have examined the comparative static effects of the population size and the degradation rate on environmental quality, direct offsets, and net contributions, and have compared the 
results with those derived by Yoshida and Turnbull (2021) in a similar model with consumption externalities. The analysis has been conducted for several utility functions which are familiar in the literature of public good provision under monopolistic competition: the CES function, the Krugman-Pecorino (KP) function, and the Krugman-Mondal (KM) function. We have demonstrated that whether labor supply is institutionally constrained or not, as the population size increases, environmental quality decreases and converges to zero, but offsets increase and converge to the degradation rate of environmental quality, so that the carbon neutrality theorem holds: net contributions are zero. These comparative static results, which are independent of the specification of the utility function, are different from those with consumption externalities. We have also shown when labor supply is endogenous, the comparative static results of the degradation rate are the same as those with consumption externalities.

We have not considered the effect of preference for diversity among the differentiated goods (the PFD effect), but the PFD effect does not affect the main conclusions of the paper, for example, Proposition 1 in Section 4 holds even if this effect exists. We also have not referred to the comparative statics of other parameters except for the population size and the degradation rate. It will be useful to briefly comment on them. First, the results of the ambient level of environmental quality and the fixed and marginal cost of monopolistic production are the same as those with consumption externalities. Second, all environmental variables are increasing in the labor productivity of the environmental good in the KP and KM cases, but in the CES case, they are increasing in this productivity when environmental quality and the composite good are not complements. Third, all environmental variables are independent of the exogenous leisure in the KP case, but they are increasing in it in the CES and KM cases.

There are many practical examples of voluntary reductions in production that can improve the environment. As mentioned in the Introduction, telework for office workers in response to the COVID-19 pandemic is a closely related phenomenon, and it is already well-documented to reduce teachers' productivity in schools. It is also an obvious policy to reduce carbon emissions, the theme of this paper. The downsizing of automobiles that occurred in the 1970s is another example from household production. That is, people don't buy automobiles to look at them (usually), they are used to enable other household activities. Smaller automobiles make it difficult or impossible to do some activities (carrying large objects) and force reductions in other (size of car pools). Organic farming is yet another example. Despite the occasional extravagant claims of proponents, no one has yet demonstrated productivity improvements from organic methods of pest and weed control.

That these examples occur at the edges of the industrial economy is no accident. All of these examples involve workers who have substantial control over their working schedules and production methods. The exception among these examples is telework, which must be enabled by the employer. We cannot say much about employers, i.e. corporate-social-responsibility-induced reductions in output, as they are motivated by profits in our model (and there are at present no good alternatives for general equilibrium modeling, while the neoclassical tradition suggests the Darwinian perspective that profit maximization is the necessary outcome of 
natural selection). On the other hand, workers employed by such corporations are almost universally bound by contract (whether explicit or implicit) to provide a certain amount of given types of labor to the employer, which we model as fixed labor supply. They cannot engage in reduced production. We do not here argue for either profit maximization or inflexible labor contracts, except to note that they fit the stylized facts tolerably well.

An obvious question is, "Aren't these examples quite marginal?" There are three answers to that. First, our model provides a rigorous but plausible foundation for the theoretical existence of voluntary reductions in production to ameliorate degradation of the environment, even in the presence of alternative means to that end. Second, we show that in the large economy, carbon neutrality holds. That is, the reduction in per worker output due to this motivation is sufficiently large as to offset the environmental burden of an additional worker. That is surely a significant effect at the macro level. Finally, as usual in these models we assume full rationality and perfect information on the part of our agents. But in practice, information about the effectiveness, and even the true costs, of these actions is quite imperfect. Education will be necessary. As we have seen in the COVID-19 pandemic in Japan as well as in the U.S., it is frequently the case that government regulations are not enforced . In such situations it is reasonable to interpret the compliance that does occur as voluntary reductions in productive activity. It is very likely that similar effects will only grow in importance to carbon dioxide emission reduction as the perception of a climate crisis grows. Aspirational government regulations with no enforcement teeth can serve as an effective educational tool, alongside conventional advocacy for "greening"-including downsizing — the economy.

Acknowledgements An early version of this paper was presented in a seminar held at the University of Tsukuba. We would like to thank the participants in the event for constructive comments. We also thank an editor of this journal, who encouraged us to comment on the policy implications of our results, improving the presentation greatly. The authors acknowledge financial support from the Ministry of Education, Culture, Sports, Science and Technology of Japan under Grants-in-Aid for Scientific Research C (No. 209K1570).

\section{References}

Andreoni, J. (1988). Privately provided public goods in a large economy: The limits of altruism. Journal of Public Economics, 35, 57-73.

Bag, P. K., \& Mondal, D. (2014). Group size paradox and public goods. Economics Letters, 125, 215-218.

Bergstrom, T. C., Blume, L., \& Varian, H. (1986). On the private provision of public goods. Journal of Public Economics, 29, 25-49.

Ihori, T. (1999). Environmental externalities and growth. In R. Sato, R. V. Ramachandran, \& K. Mino (Eds.), Global Competition and Integration. Dordrecht: Kluwer Academic Press.

Kotchen, M. J. (2009). Voluntary provision of public goods for bads: A theory of the environmental offsets. Economic Journal, 119, 883-899.

Krugman, P. R. (1980). Scale economies, product differentiation, and the pattern of trade. American Economic Review, 70, 950-959.

Krugman, P. R. (1981). Intraindustry specialization and the gains from trade. Journal of Public Economics, 89, 959-973. 
Mondal, D. (2013). Public good provision under monopolistic competition. Journal of Public Economic Theory, 15, 378-396.

Pecorino, P. (2009). Monopolistic competition, growth and public good provision. Economic Journal, 119, 298-307.

Shibata, H. (1998). Voluntary control of public bad is independent of aggregate wealth: The second neutrality theorem. Public Finance, 53, 269-284.

Vicary, S. (2000). Donations to a public good in a large economy. European Economic Review, 44, 609-618.

Yoshida, M. (1998). Nash equilibrium dynamics of environmental and human capital. International Tax and Public Finance, 5, 357-377.

Yoshida, M., \& Turnbull, S. J. (2021). Voluntary provision of environmental offsets under monopolistic competition. International Tax and Public Finance, 28, 965-994.

Publisher's Note Springer Nature remains neutral with regard to jurisdictional claims in published maps and institutional affiliations. 